Article

\title{
Analysis of the Relationships between Tourism Efficiency and Transport Accessibility-A Case Study in Hubei Province, China
}

\author{
Yaobin Wang ${ }^{1}$, Meizhen Wang ${ }^{1, *}$, Kongming $\mathrm{Li}^{2}$ and Jinhang Zhao ${ }^{1}$ \\ 1 College of Tourism, Northwest Normal University, Lanzhou 730070, China; 003279@nwnu.edu.cn (Y.W.); \\ 2019212632@nwnu.edu.cn (J.Z.) \\ 2 College of Geography and Environmental Science, Northwest Normal University, Lanzhou 730070, China; \\ 2018222416@nwnu.edu.cn \\ * Correspondence: 2020212998@nwnu.edu.cn
}

Citation: Wang, Y.; Wang, M.; Li, K.; Zhao, J. Analysis of the Relationships between Tourism Efficiency and Transport Accessibility_A Case Study in Hubei Province, China. Sustainability 2021, 13, 8649. https:// doi.org/10.3390/su13158649

Academic Editor:

Olha V. Prokopenko

Received: 22 June 2021

Accepted: 30 July 2021

Published: 3 August 2021

Publisher's Note: MDPI stays neutral with regard to jurisdictional claims in published maps and institutional affiliations.

Copyright: () 2021 by the authors. Licensee MDPI, Basel, Switzerland. This article is an open access article distributed under the terms and conditions of the Creative Commons Attribution (CC BY) license (https:// creativecommons.org/licenses/by/ $4.0 /)$.

\begin{abstract}
There is a close relationship between tourism efficiency and transport accessibility, but there is little research on the topic. This paper takes 17 administrative units in Hubei Province as the research object, evaluates their tourism efficiency from 2011 to 2017 and transportation accessibility in 2011 and 2017, and explores the temporal and spatial correlation between the two. The results showed that, from 2011 to 2017, tourism efficiency of Hubei province was high and steadily improving, space non-equilibrium gradually decreased, and differences shrank. In 2011 and 2017, the province had a good tourism transport accessibility, and the spatial distribution pattern was high in the east and low in the west. At the same time, tourism transport continued to improve, and spatial imbalance declined. In 2011 and 2017, the coupling and coordination of tourism efficiency and its decomposition efficiency and transport accessibility in Hubei Province were both good, indicative of the development of a tourism economy and the improvement of tourism transport facilities in all regions of the province. There is also a poor spatial matching of tourism efficiency and its decomposition efficiency with transport accessibility during the study period. This study suggested that the tourism efficiency and transport accessibility increased in Hubie province, but the coupling and spatial match remain not very good. Therefore, each region should improve the spatial match and coupling degree of tourism efficiency and transport accessibility, and enhance the sustainability of tourism development.
\end{abstract}

Keywords: DEA model; GIS spatial network analysis; tourism efficiency; tourism transport accessibility; spatiotemporal correlations

\section{Introduction}

Since China's reform and opening up, tourism has played a critical role in the development of the national economy [1,2]. With high-speed rail as its backbone, China's railway has seen great achievements and offers new opportunities for the tourism economy [3,4]. With the development of China's tourism industry, the focus of tourism research has turned to efficiency and sustainable development [5].

As a research category of economics, efficiency measurement usually involves input and output, which is a scale to represent the relative relationship between input and output. Tourism efficiency is to reveal the relationship between tourism input and output through the proportional relationship. That is, the maximum output that can be achieved per unit of factor input. It is an important indicator to measure the overall allocation status and utilization efficiency of regional tourism resources [6,7]. Previous studies mainly examined the operating efficiency of tourist hotels [8,9], travel agencies and listed tourism companies [10-12], and the efficiency of tourist attractions [7,13,14], tourism transport [15], urban tourism [16], urban agglomeration or regional tourism input and output $[17,18]$, and the relationship between driving mechanism of tourism efficiency 
and decomposition efficiency $[13,14]$. Some mathematical analysis models have been widely used in empirical research, such as data envelopment analysis (DEA) $[13,14,16-18]$, stochastic frontier analysis (SFA) $[2,19]$ and constant elasticity of substitution production function (CES) $[2,20]$. As an important factor in the development of tourism, tourism transport has also attracted great attention from the academic community. On the one hand, with the rapid development of tourism, people's demand for traffic conditions is increasing, which promotes the improvement of public transportation system to a certain extent; on the other hand, the continuous improvement of the public transportation system enhances regional accessibility and thus the number of tourists further increases, which in turn promotes the continuous development of the tourism industry. There is an interactive relationship of interdependence, mutual promotion, and complementarity between them [21]. At present, scholars' research on tourism transportation mainly focuses on tourism transportation planning [22,23], the interaction and coordinated development of tourism and transportation [24,25], the status and role of tourism transportation in regional tourism system [26,27], and the accessibility of tourism transportation [28,29]. Specially, the research on tourism transport accessibility is the most extensive, mainly covering the transport accessibility of scenic spots, important tourist cities [30,31], urban green parks [32], and regional tourism. The studies relied on GIS spatial network analysis [32,33], raster cost weighted distance algorithm, and weighted average travel time [30,33]. Although previous studies of tourism efficiency and transport accessibility were comprehensive and systematic, there is a lack of research on the relationship between them, especially at the regional level. Cao et al. [2] have evaluated the tourism efficiency of scenic spots and its spatiotemporal relationship with transport accessibility, but they were interested in tourist attractions and their work offered no theoretical guidance for the development and improvement of the regional tourism system. The occurrence and development of tourism take the space system as the material carrier [30]. Regional tourism is a complex open system, and tourism efficiency and transport accessibility are important indicators of the development of a regional tourism system. A health and sustainable tourism system can generally reconcile them in the meantime, and can realize a synergetic relationship between them $[25,26]$. The poor match between them may not be harmful, but is, at least, not beneficial to the sustainable development of tourism systems [34,35]. Understanding the relationship between the two, from the perspective of a tourism system, will help clarify the coupling and coordination of the tourism economic subsystem and the tourism transport subsystem within the regional tourism system, and contribute to the healthy and sustainable development of regional tourism industries.

At present, with the continuous development of the Chinese economy, the intensity and scale of tourism resource development are increasing, the number of tourism hotels is rising, and tourism promotion and marketing efforts are increasing each year. China's tourist industry had shown impressive growth. However, with the gradual saturation of tourism element input, the model of tourism economic growth driven by continuous investment in tourism has become ineffective $[3,18,36]$. Relying on a fast and perfect transport network, improving the quality and efficiency of tourism economic development, and realizing the transformation, upgrading and intensive development of the tourism industry are issues that urgently need to be resolved in the development of tourism industry. Hubei Province is located in the middle reaches of the Yangtze River in Central China, known as the "Nine Provinces Thoroughfare". It has a superior geographical location and rich tourism resources and has a pivotal position and role in the social and economic development of the Yangtze River Basin and even Central China. In recent years, with the deployment and implementation of a series of national and regional development strategies such as the Yangtze River Economic Belt, the Wuhan Metropolitan Circle in Eastern Hubei, and the Eco-cultural Tourism Circle in Western Hubei, Hubei Province's tourism and transport industries have achieved rapid development [35]. Based on it, this paper aims to quantitatively simulate the spatiotemporal evolution characteristics of tourism efficiency and transport accessibility in the development of Hubei Province's 
tourism system, as well as the relationship between the two. This paper will present a theoretical basis for the improvement of tourism efficiency in Hubei Province and even the middle and lower reaches of the Yangtze River, the rational allocation of transport networks, and the sustainable development of tourism.

\section{Materials and Methods}

\subsection{Overview of the Study Area}

Hubei Province is located in central China at the middle and lower reaches of the Yangtze River (Figure 1). The terrain is high in the west and low in the east. The western is a mountainous area, and the eastern is a relatively flat area where the provincial capital Wuhan is located [36]. Hubei Province has 1 sub-provincial city, 11 prefecture-level cities, 1 autonomous prefecture, three directly managed cities, and one forest area. They are Wuhan; Huangshi, Shiyan, Yichang, Xiangyang, and Ezhou, Jingmen City, Xiaogan City, Jingzhou City, Huanggang City, Xianning City, Suizhou City; Enshi Tujia and Miao Autonomous Prefecture; Xiantao City, Qianjiang City, Tianmen City; Shennongjia Forest District [37]. In 2009, Hubei Province has proposed the "two circles and one belt" strategic layout (i.e., The Yangtze River Economic Belt, the Wuhan Metropolitan Circle in Eastern Hubei, and the Eco-cultural Tourism Circle in Western Hubei), which offered macro policy guidance for tourism development in this province [35] and great contributed to the development of tourism. There are two main reasons for choosing Hubei Province as the case location. On the one hand, Hubei Province has a long history and is rich in natural and cultural tourism resources; On the other hand, Hubei Province has convenient transportation, with railways, expressways and provincial highways forming the backbone of the provincial transportation network. Hubei, which has both high-quality tourism resources and convenient transportation, is the best choice for studying the relationship between tourism efficiency and transportation accessibility.
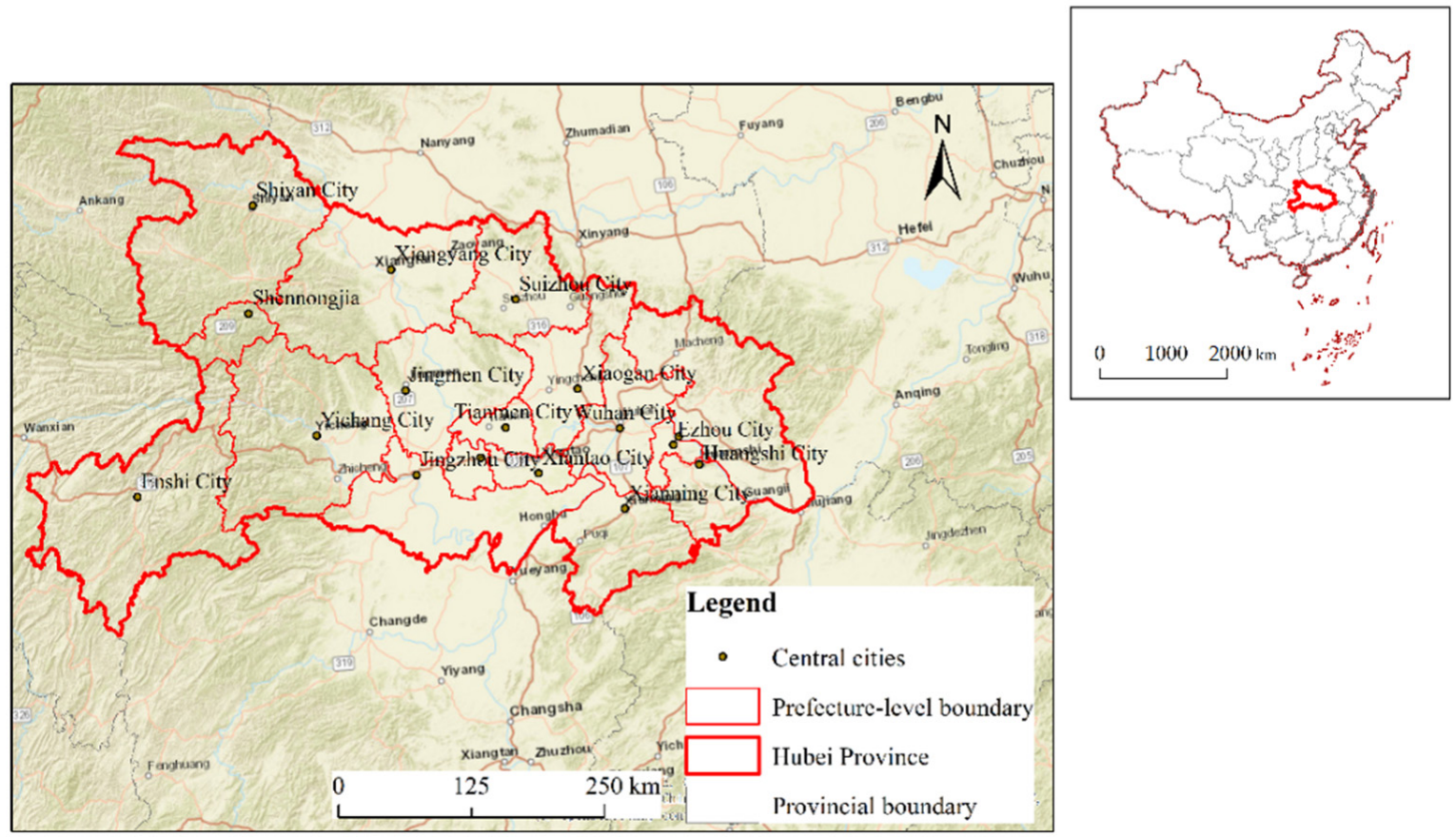

Figure 1. The Hubei Province.

\subsection{Selection of Indicators and Data Sources}

Th selection of indicators measuring the tourism development should consider the suitability and data availability. According to previous studies $[2,18,27,38]$ and the data availability, six indicators that reflect the tourism efficiency of Hubei Province to the greatest 
extent are selected (Table 1). The four input indicators are the number of star-rated hotels (units), the number of employees in the tertiary industry (ten thousand people), the number of travel agencies (units) and the number of A-level scenic spots (units). The two output indicators are tourism revenue (100 million yuan $=12,885,269.6$ Euro $=15,418,060.7$ US dollars). and the number of tourists received (10,000 person-times). In addition, there is a lag between input and output (The input and the output don't match in the current year). Therefore, when calculating tourism efficiency, the input elements of the current year should correspond to the output level of the following year $[2,13,14]$. These data are derived from the Statistical Yearbook of Hubei Province, the Statistical Bulletin of National Economic and Social Development, and the Statistical Bulletin of Tourism Development of Yichang City from 2011 to 2018.

Table 1. Selection of indicators.

\begin{tabular}{clc}
\hline Types of Indicators & \multicolumn{1}{c}{ Name of Indicators } & Unit \\
\hline \multirow{3}{*}{ Input indicators } & $\begin{array}{l}\text { number of star-rated hotels } \\
\text { the number of employees in the } \\
\text { tertiary industry } \\
\text { the number of travel agencies } \\
\text { the number of A-level } \\
\text { scenic spots }\end{array}$ & units \\
& ten thousand people & units \\
& tourism revenue & units \\
\hline Output indicators & the number of tourists received & $\begin{array}{c}\text { Euro } / 15,418,060.7 \text { US dollars } \\
10,000 \text { person-times }\end{array}$ \\
\hline
\end{tabular}

Using ArcGIS10.5, the Hubei Province Traffic Map (2014 Edition) issued by the China Map Publishing House was georeferenced and vectorized. Then, the transport networks of Hubei Province in 2011 and 2017 were extracted; these consisted of highways, national roads, provincial roads, and railways, and the spatial reference was set to WGS_1984_UTM. Administrative central cities (towns) in 17 regions of Hubei Province (Wuhan city, Yichang city, Xiangyang city, Shiyan city, Enshi city, Jingzhou city, Jingmen city, Suizhou city, Xiaogan city, Tianmen city, Qianjiang city, Xiantao city, Huangshi city, Huanggang city, Ezhou city, Xianning city and Songbai town) are used as nodes in the transport network to divide the roads. Then, the roads between nodes are assigned attributes, including line length, speed and driving time, which are used as the basis of GIS network analysis. The data of highway traffic routes and mileage are from the 2011-2017 statistical yearbooks of various regions. According to the "Technical Standards for Highway Engineering of China" (JTGB01-2014), and considering the terrain of Hubei Province, the road running time between nodes is calculated by setting the speed for the road network. According to the railway operation timetable published on the official website of the Ministry of Railways of China, the shortest train operation time between nodes is as the railway traffic operation time between those nodes. Considering that the 2011 railway operation timetable was difficult to obtain, the 2017 data has been selected as a substitute (except for the high-speed rail and EMU trains that were not running in 2011).

\subsection{Research Methods}

\subsubsection{DEA Model}

The DEA model is a quantitative analysis method to evaluate the relative effectiveness of comparable units of the same type by using the method of linear programming according to multiple input indicators and multiple output indicators and has been wildly used in previous. Domestic scholars have begun to use the DEA model to study tourism efficiency, which mainly includes urban tourism efficiency [38], tourism enterprise operating efficiency [39], hotel operating efficiency [40], and tourism ecological efficiency [41,42]. In recent years, many scholars have also tried to use the DEA model to study the efficiency of tourism in poverty alleviation [43]. The DEA model (data envelopment analysis) was 
proposed by operations researcher Charles and Cooper et al. in 1978 [44]. This model including three types: CCR model, BCC model and super efficiency model. The CCR and BCC models are the most common. The former assumes that the return to scale is constant, but the latter assumes that it is variable. In the tourism industry, input variables are controllable but output variables are not. Therefore, the input-oriented BCC model with variable returns to scale was selected in this study [45]. The equation is as follows:

$$
\left\{\begin{array}{c}
\min \left[\theta-\varepsilon\left(\sum_{i=1}^{w} S_{i}^{-}+\sum_{r=1}^{m} S_{r}^{+}\right)\right] \\
\text {s.t } \sum_{j=1}^{n} x_{i j} \lambda_{j}+S_{i}^{-}=\theta x_{i 0}(i=1,2,3, \ldots \ldots . ., w) \\
\sum_{j=1}^{n} y_{i j}-S_{r}{ }^{-}=y_{r 0}(r=1,2,3, \ldots \ldots . ., m) \\
\sum_{j=1}^{n} \lambda_{j}=1(j=1,2,3, \ldots \ldots \ldots, n)
\end{array}\right.
$$

where $w$ is the number of decision-making units, $m$ is the number of input elements, and $n$ is the number of output elements. $x_{i j}$ represents the variable of the input element $i$ in the decision-making unit $j$, and $y_{r j}$ represents the variable of the output element $r$ in the decision-making unit $j$. Here, $\lambda$ is the unit combination coefficient, whose value is greater than or equal to zero; $\theta$ is the efficiency evaluation index, and $\varepsilon$ is the non-Archimedean infinitesimal quantity. $S_{i}{ }^{-}$and $S_{r}{ }^{+}$are slack variables, and their values are greater than or equal to zero.

The BCC model decomposes overall efficiency (OE) into pure technological efficiency (PTE) and scale efficiency (SE). Overall efficiency is the ratio between output utility and production resource input under the conditions of maximum output in each region's tourism industry. Pure technical efficiency refers to the degree of utilization of technology. Scale efficiency is the effective degree of production scale, which reflects whether the operation of the decision-making unit is carried out under the most appropriate investment scale conditions $[44,45]$. The relationship among them is $\mathrm{OE}=\mathrm{PET} \times \mathrm{SE}$. When its value is one, it means that the efficiency is effective and there is no redundancy in factor input, and when it is less than one, it means that the efficiency is invalid and there is redundancy in factor input.

\subsubsection{Dijkstra Algorithm and Spatial Network Analysis}

Previous studies have shown that the region's central cities (towns) are tourism nodes in regional tourism and transit point for tourists traveling between tourist attractions [35]. Therefore, a multi-level transport network based on tourism nodes and using GIS network analysis to evaluate the transport accessibility of regional tourism can reveal the difficulty and balance of tourism flows between nodes. This paper uses GIS network analysis to study tourism transport accessibility in Hubei Province.

The Dijkstra algorithm can calculate the shortest path between two vertices [46]. Based on the transport network of Hubei Province, the Dijkstra algorithm is implemented using ArcGIS10.5 network analysis tools to calculate the fastest travel time and the shortest travel distance between transport nodes.

\subsubsection{Calculation of Accessibility Coefficient}

In this paper, the weighted average travel time model [30] is used to calculate the tourism transport accessibility coefficient. Its equation is as follows:

$$
A_{i}=\sum_{j=1}^{n} T_{i j} M_{j} / \sum_{j=1}^{n} M_{j}
$$

where $T$ represents the shortest travel time from node $i$ to node $j$ in the region, which is obtained by GIS network analysis. $M$ is the weight of node $j$, and the gross national product 
of node $j$ is usually selected. Given that the subject of this paper is the tourism industry, the tourism income of node $j$ is selected here, and $n$ is the number of nodes excluding node $i$ and $A i$ represents the accessibility level of node $i$. The smaller the value of $A$, the better the accessibility of node $I$; and the larger the value of $A$, the less the accessibility.

\subsubsection{Coupling and Coordination Degree Model}

Coupling degree describes the degree of interaction between systems or elements. Coordination degree is a kind of benign correlation between two or more systems or system elements, which represents the healthy development of multiple systems or elements. The degree of coupling and coordination indicates the degree of benign coupling in the interaction, which reflects the relationships between tourism elements in a tourism system. A coupling and coordination degree model $[47,48]$ can measure the coupling and coordination relationships between regional transport accessibility and tourism efficiency, and show the coordinated development status of regional tourism economy subsystem and tourism transport subsystem. Its equation is as follows:

$$
\begin{gathered}
C=2\left\{[X \times Y] /[X+Y]^{2}\right\}^{1 / 2} \\
T=\alpha X+\beta Y \\
D=\sqrt{C \times T}
\end{gathered}
$$

where $X$ and $Y$ represent the standardized scores of tourism efficiency and transport accessibility, and their values range from 0 to $1 . \alpha$ and $\beta$ are the weights of tourism efficiency and transport accessibility, and both take a value of 0.5 . Here, $C$ is the coupling degree between tourism efficiency and transport accessibility, and $T$ is the coordination degree between tourism efficiency and transport accessibility, and the value range is $[0,1]$, while $D$ is the degree of coupling and coordination, and the value range is $[0,1]$. The larger the value of $D$, the better the coupling and coordination between tourism efficiency and transport accessibility.

\subsubsection{Bivariate Local Spatial Autocorrelation Analysis}

Bivariate local spatial autocorrelation analysis can reveal the spatial variation of the correlation between variables. In this paper, the bivariate local indicators of spatial association (LISA)was used to explore the evolutionary characteristics of the spatiotemporal correlation between tourism efficiency and transport accessibility [49]. Its equation is as follows:

$$
I_{k l}^{I}=Z_{k}^{i} \sum_{j=1}^{n} W_{i j} Z_{l}^{i}
$$

where $I_{k l}^{i}$ is the spatial correlation index of the attributes $k$ and $l$ on the spatial unit $i$; $w_{i j}$ is the spatial weight matrix between the spatial unit $i$ and the unit $j$. In $z_{k}^{i}=\left(x_{k}^{i}-\bar{x}_{k}\right) / \sigma_{k}, z_{l}^{i}=$ $\left(x_{l}^{i}-\bar{x}_{l}\right) / \sigma_{l}, x_{k}^{i}$ and $x_{l}^{i}$ are the values of attributes $k$ and $l$ on space unit $i . \bar{x}_{k}$ and $\bar{x}_{l}$ are the average values of attributes $k$ and $l$, and $\sigma_{k}$ and $\sigma_{l}$ are the variances of attributes $k$ and $l$, respectively.

\section{Results}

This paper mainly uses mathematical statistics method to analyze the collected data, and studies the tourism efficiency, traffic accessibility and the relationship between them in Hubei Province. The research process is mainly divided into the following three parts: using the DEA model to study the spatiotemporal evolution characteristics of tourism efficiency in Hubei Province, using GIS network analysis and traffic accessibility coefficient algorithm to study the spatiotemporal evolution characteristics of traffic accessibility in Hubei Province, and then using coupling coordination degree model and spatial autocorrelation analysis 
to study the spatiotemporal correlation characteristics of tourism efficiency and traffic accessibility. The results are as follows.

\subsection{Spatiotemporal Evolution Characteristics of Tourism Efficiency in Hubei Province}

The descriptive statistics of tourism efficiency in Hubei Province in 2011, 2013, 2015, and 2017 are shown in Table 2. From 2011 to 2017, the tourism efficiency of Hubei Province has shown an upward trend, and the sustainable development capacity of the tourism industry has gradually increased. In 2011, 2013, 2015 and 2017, the number of regions with optimal overall efficiency (OE) was 3, 3, 3, and 6, respectively, accounting for 17.6\%, $17.6 \%, 17.6 \%$, and $35.2 \%$ of the regions. The average overall efficiency (OE) increased from 0.66 in 2011 to 0.71 in 2017. The number of regions with higher overall efficiency than average OE was 8, 9, 9 and 9. From 2011 to 2017, the overall level of pure technical efficiency (PTE) was high, and the average values of PTE were 0.834, 0.872, 0.894, and 0.879 in 2011, 2013, 2015, and 2017, respectively. Among them, 11, 10, 11, and 12 regions reached the average level, and the number of efficient regions was 7, 9, 8, and 10 in 2011, 2013, 2015 and 2017. In terms of scale efficiency (SE), the number of effective regions in 2011, 2013, 2015 and 2017 was 3, 3, 3, 6, and the average values were $0.810,0.787,0.781$, and 0.819. There is a trend of initial decline followed by a slight rise, which showed that Hubei Province's scale of tourism investment is compatible with tourism demand. In addition, the Global Moran's I, coefficient of variation and standardized variance used to characterize the spatial variability and spatial autocorrelation of tourism efficiency showed that the spatial aggregation effect of tourism efficiency and its decomposition efficiency in Hubei Province is not significant $(p>0.05)$. It remained stable during the study period (Table 2$)$.

Table 2. The descriptive statistics of tourism efficiency in Hubei Province from 2011 to 2017.

\begin{tabular}{|c|c|c|c|c|c|c|c|c|c|c|c|c|}
\hline \multirow{2}{*}{$\begin{array}{l}\text { Statistical } \\
\text { Variables }\end{array}$} & \multicolumn{4}{|c|}{ Overall Efficiency } & \multicolumn{4}{|c|}{ Pure Technology Efficiency } & \multicolumn{4}{|c|}{ Scale Efficiency } \\
\hline & 2011 & 2013 & 2015 & 2017 & 2011 & 2013 & 2015 & 2017 & 2011 & 2013 & 2015 & 2017 \\
\hline $\begin{array}{c}\text { Amount of area } \\
\text { with optimal } \\
\text { efficiency }\end{array}$ & 3 & 3 & 3 & 6 & 7 & 9 & 8 & 10 & 3 & 3 & 3 & 6 \\
\hline Minimum & 0.165 & 0.134 & 0.110 & 0.182 & 0.463 & 0.545 & 0.585 & 0.477 & 0.165 & 0.134 & 0.110 & 0.182 \\
\hline Standard deviation & 0.265 & 0.273 & 0.278 & 0.285 & 0.202 & 0.164 & 0.140 & 0.181 & 0.262 & 0.270 & 0.277 & 0.272 \\
\hline Mean value & 0.660 & 0.678 & 0.694 & 0.710 & 0.834 & 0.872 & 0.894 & 0.879 & 0.810 & 0.787 & 0.781 & 0.819 \\
\hline Variable coefficient & 0.402 & 0.403 & 0.401 & 0.401 & 0.243 & 0.188 & 0.157 & 0.206 & 0.323 & 0.343 & 0.355 & 0.332 \\
\hline Global Moran's I & -0.01 & 0.085 & 0.169 & 0.202 & 0.024 & 0.031 & 0.148 & -0.004 & 0.278 & 0.25 & 0.244 & 0.256 \\
\hline
\end{tabular}

The OE can fully reflect the input-output proportional utility of the production elements of the tourism industry in each region. With reference to the existing classification standard [50], the overall tourism efficiency is divided into four levels: $\mathrm{OE} \leq 0.4$, extremely low; $0.4<\mathrm{OE} \leq 0.6$, low; $0.6<\mathrm{OE} \leq 0.8$, high; $\mathrm{OE} \geq 0.8$, extremely high. With reference to the Appendix A Table A1, overall tourism efficiency is spatialized processing (Figure 2). In general, during the study period, the province's tourism efficiency level was high and steadily improved. The number of regions with a high or extremely high OE level increased from 8 in 2011 to 11 in 2017, while the number of regions with a low or extremely low OE level decreased from 9 in 2011 to 6 in 2017. Among the 17 regions of Hubei Province, the improvement of tourism efficiency in Yichang, Enshi and Shiyan is the most obvious, all of which were high or extremely high in 2017. This could be due to the optimization of the layout and scale of tourism element input in the construction of the Eco-cultural Tourism Circle in Western Hubei, which improves the utilization of tourism resources and enhances the pure technical efficiency of regional tourism $[18,35]$. The tourism efficiency of Wuhan, Xianning, Jingzhou, Jingmen, Suizhou, Xiangyang and Shennongjia remained high, indicating that these regions took full advantage of tourism resources, and the layout and scale of tourism element inputs were reasonable. However, the tourism efficiency of Tianmen, Qianjiang, Ezhou, Xiantao, Huangshi and Huanggang was always low. On the one hand, 
this was caused by its poor endowment of tourism resources; on the other hand, this could be attributed to the insufficient "trickle-down effect" and the strong "polarization effect" of the core city, Wuhan, on the peripheral areas $[35,50]$. In other words, a large amount of labor and capital in the surrounding areas has flowed into the central city, Wuhan, but the technical support and management experience the surrounding areas acquired from the central city was very limited.
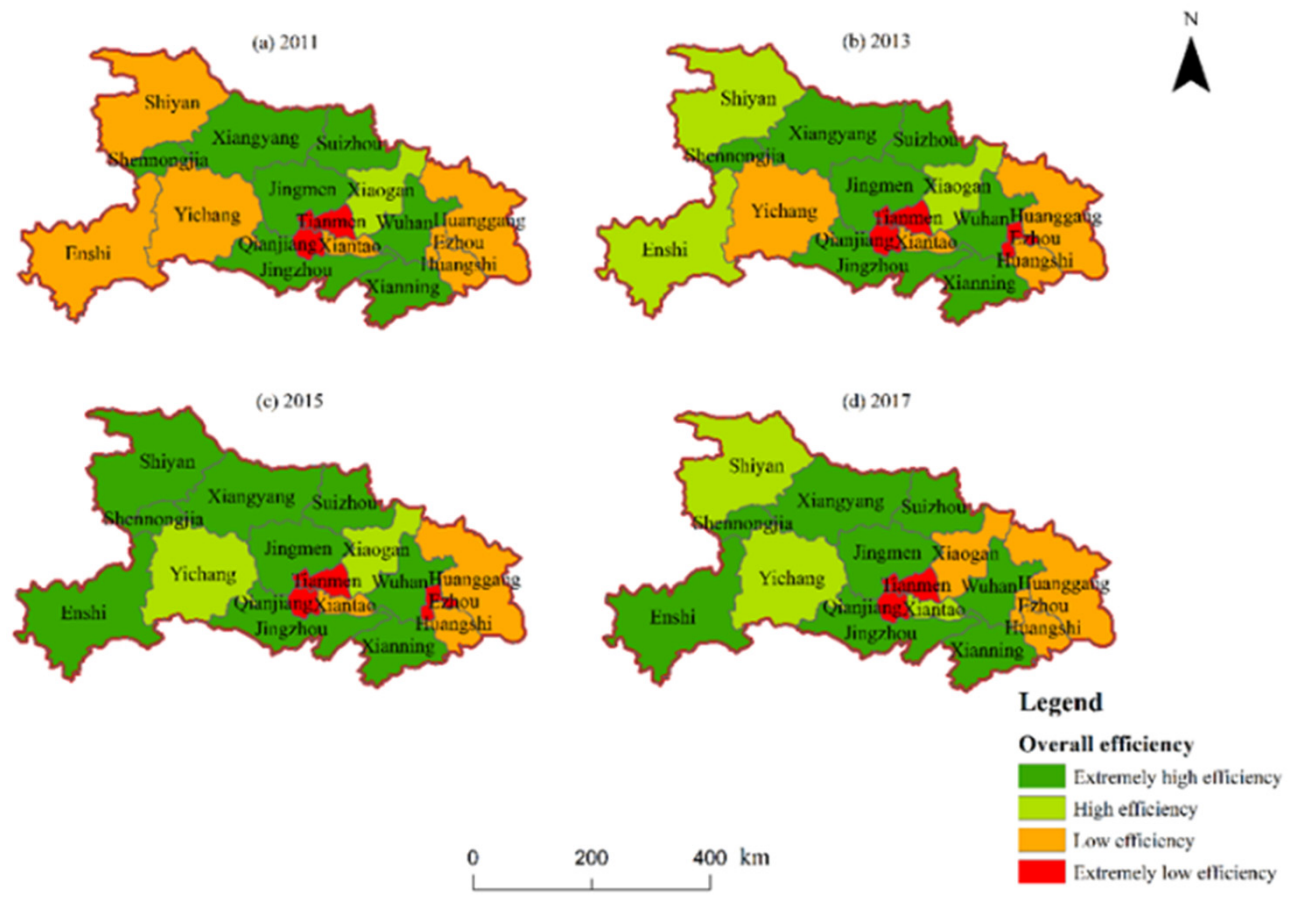

Figure 2. The spatiotemporal distribution of OE in Hubei Province.

\subsection{Spatiotemporal Evolution of Tourism Transport Accessibility in Hubei Province}

Using GIS network analysis and the algorithm of transport accessibility coefficients, tourism transport accessibility coefficients of regions in Hubei Province were obtained (Table 3). The average tourism transport accessibility coefficients in Hubei Province decreased from 2.25 in 2011 to 1.99 in 2017, indicating that the overall accessibility increased by $11 \%$. Among Hubei's 17 subregions, the accessibility of Wuhan has increased by $9 \%$, while that of Yichang, Jingzhou, Huangshi, Huanggang and Ezhou has increased by more than $20 \%$, with the most obvious improvement being in traffic conditions. The accessibility levels of Xiaogan, Jingmen, and Shennongjia showed a slight downward trend, with respective change rates of $3 \%, 6 \%$, and 10\%. In 2011 and 2017, the tourism transport accessibility in Wuhan was the highest in the province, while the transport accessibility of Enshi and Shennongjia in Western Hubei was the lowest. In addition, the Global Moran's I of transport accessibility in Hubei Province in 2011 and 2017 were 0.662 and 0.604, indicating that the traffic conditions in Hubei Province have significant spatial agglomeration effects $(p<0.05)$ (Table 3). 
Table 3. Tourism transport accessibility of Hubei Province in 2011 and 2017.

\begin{tabular}{cccc}
\hline Area & $\mathbf{2 0 1 1}$ & $\mathbf{2 0 1 7}$ & Rates \\
\hline Wuhan & 1.17 & 1.07 & -0.09 \\
Ezhou & 1.67 & 1.29 & -0.23 \\
Huanggang & 1.78 & 1.35 & -0.24 \\
Xiantao & 1.62 & 1.42 & -0.12 \\
Xiaogan & 1.42 & 1.47 & 0.03 \\
Qianjiang & 1.73 & 1.47 & -0.15 \\
Xianning & 1.75 & 1.52 & -0.13 \\
Huangshi & 1.91 & 1.53 & -0.20 \\
Tianmen & 1.71 & 1.53 & -0.11 \\
Jingzhou & 2.15 & 1.59 & -0.26 \\
Suizhou & 1.93 & 1.78 & -0.08 \\
Yichang & 2.61 & 1.80 & -0.31 \\
Jingmen & 2.04 & 2.17 & 0.06 \\
Xiangyang & 2.55 & 2.22 & -0.13 \\
Shiyan & 3.63 & 3.51 & -0.03 \\
Enshi & 4.48 & 3.70 & -0.18 \\
Shennongjia & 4.03 & 4.45 & 0.10 \\
Mean value & 2.25 & 1.99 & -0.11 \\
Global Moran's I & 0.662 & 0.604 & - \\
\hline
\end{tabular}

In terms of spatial distribution (Figure 3), the tourism transport accessibility in Hubei Province in 2011 and 2017 was high in the east and low in the west. This distribution pattern is related to the province's natural, social and economic conditions. The western part of Hubei is mostly mountainous with inconvenient transport, while the eastern part has many plains and hills and a dense road traffic network. In contrast, Wuhan, the political, economic, cultural and transport center of the whole province, is located in eastern Hubei. Wuhan has a strong radiating effect on the surrounding areas, unlike the more remote western region. In 2011, the transport accessibility of Hubei Province showed a decreasing distribution trend with Wuhan as the core. As the spatial distance from Wuhan increases, the radiation intensity of the core area decreases, and the transport accessibility level in the outer area also decreases. This conforms to the first law of geography: the law of distance attenuation [51]. In 2017, Wuhan was still the transport center of the province, with the significant improvement of accessibility, Yichang has gradually become the transport center of western Hubei. The tourism transport accessibility in the province began to show polarization with Wuhan in the east and Yichang in the west as the core, a finding similar to the research results of Fu et al. [35].
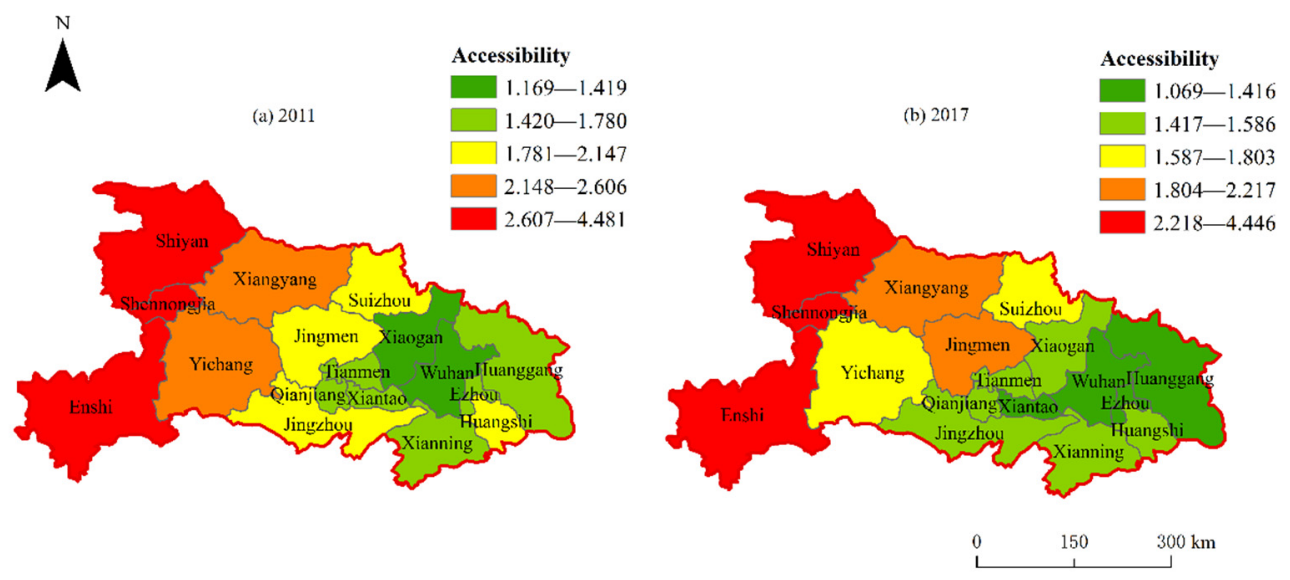

Figure 3. The spatiotemporal distribution pattern of tourism transport accessibility of Hubei Province. 


\subsection{Spatiotemporal Correlations between Tourism Efficiency and Tourism Transport Accessibility}

There tends to be a close relationship between regional tourism efficiency and transport accessibility. In theory, the higher the accessibility of regional transport, the more it can stimulate tourists' travel behavior and promote the improvement of regional tourism efficiency [18,35], that is, there is a synergistic relationship between the two. This study explores the spatiotemporal correlations between tourism transport accessibility and tourism efficiency in terms of the degree of coupling and coordination and spatial autocorrelation.

3.3.1. Analysis of the Degree of Coupling and Coordination between Tourism Efficiency and Transport Accessibility

According to previous research [52], the results of the coupling- and coordinationdegree model calculation are classified as high-quality, good, moderate, and basic coordination, and slight, moderate, and severe incoordination (Figure 4). In 2011 and 2017, Hubei Province had a high degree of coupling and coordination between overall tourism efficiency and transport accessibility. The number of regions with high-quality coordination increased from four in 2011 to five in 2017, indicating that the coupling and coordination between the tourism efficiency and transport accessibility in the province showed further improvement. In terms of the spatial characteristics of coupling coordination, although the coupling and coordination of the central and eastern regions of Tianmen, Qianjiang, Xiantao, and Huangshi were poor, the coordination of the central and eastern part is still better than in the west. This is because western Hubei region's natural topography and landforms has impeded the development of its transport system (Figure 3a,b). As for the degree of coupling and coordination between pure technical efficiency and tourism transport accessibility, the number of high-quality coordination areas increased from seven in 2011 to nine in 2017, indicating that degree of coupling and coordination in the province showed a trend of improvement. The coupling and coordination in 2011 and 2017 both presented a spatial distribution pattern of being high in the middle and low in the east and west. According to the classification of maladjustment types, Western Hubei belongs to the maladjustment of traffic lag, while eastern Hubei belongs to the maladjustment of efficiency lag, caused by the low pure technical efficiency of tourism (Figure 4c,d). The coupling and coordination between the scale efficiency and the transport accessibility was ideal. There were 10 areas with good or better coordination in 2011 and 11 in 2017. The number of high-quality coordination areas increased from seven to nine. Due to the limited traffic conditions, the coupling coordination level in Western Hubei is poor. The central and eastern parts of Hubei were better than western Hubei in terms of coupling and coordination, except some regions such as Tianmen, Qianjiang, Xiantao, and Ezhou that have poor coordination due to low tourism scale efficiency (Figure 4e,f).

According to this analysis, coupling and coordination between tourism efficiency, its decomposition efficiency, and the transport accessibility in Hubei Province from 2011 to 2017 was good, and became better. However, its spatial differentiation characteristics were obvious, and the coupling and coordination of central and eastern Hubei was better than that of western Hubei. Therefore, each region must adjust its tourism development policies and plans based on the changes in the coupling and coordination of its own tourism efficiency and transport accessibility [44]. In the follow-up process of the development of the tourism industry, all regions in western Hubei should improve their transport infrastructure and transport accessibility. However, some areas in eastern Hubei need to make use of convenient transport to make the most of their tourism resources, develop tourism products, increase tourism investment and expand the scale of tourism industry, and continue to improve the efficiency of scale. 

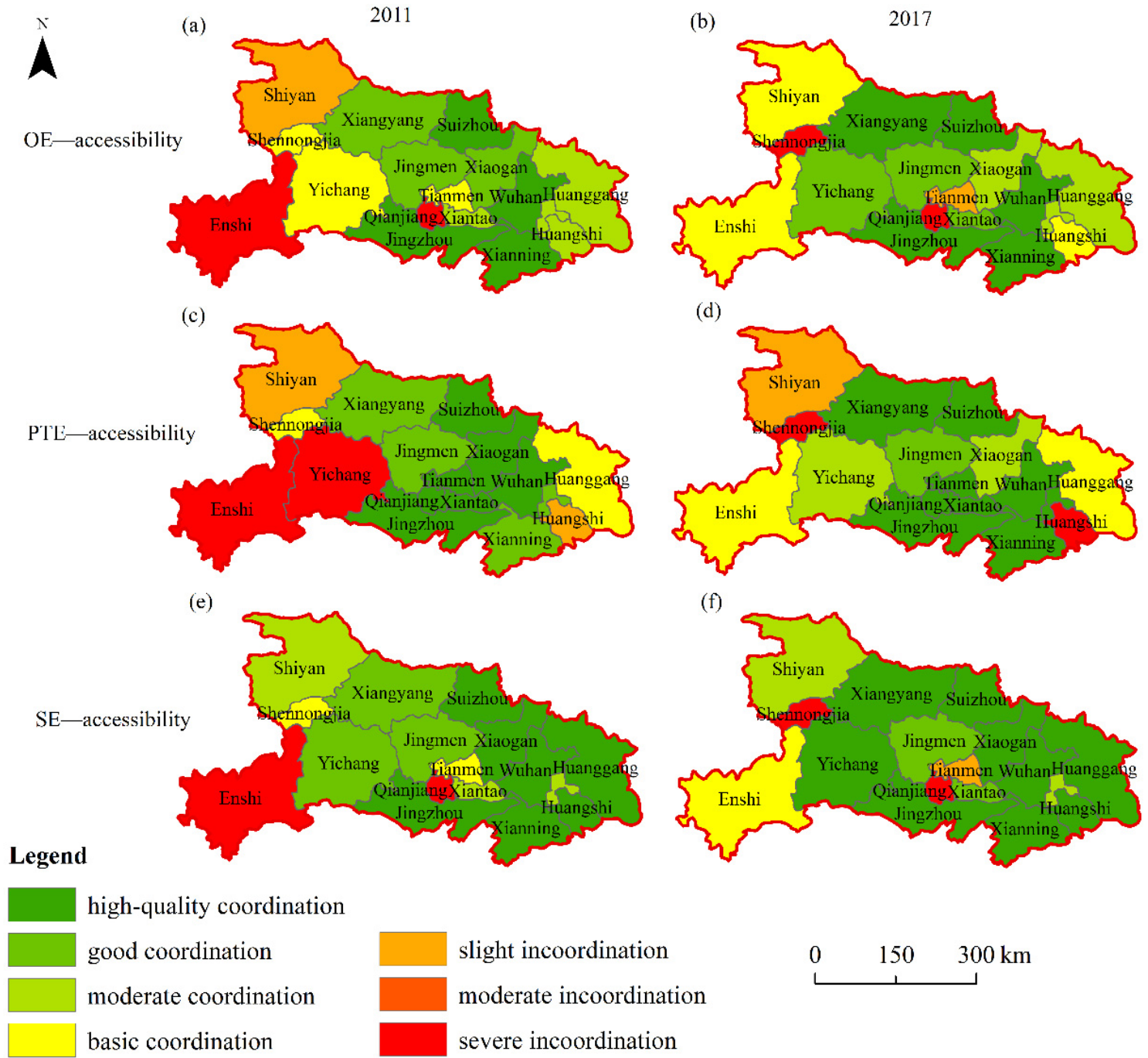

Figure 4. Coupling and coordination degree of tourism efficiency and transport accessibility in Hubei Province.

\subsubsection{Spatial Autocorrelation Analysis of Tourism Efficiency and Transport Accessibility}

The results of bivariate local spatial autocorrelation analysis showed that Hubei Province had a poor spatial matching of overall tourism efficiency and tourism transport accessibility (Figure 5). The overall tourism efficiency of regions with better transport accessibility was low, but higher in regions with poor traffic conditions. There were fewer areas with high overall tourism efficiency and good transport accessibility. The spatial agglomeration of overall tourism efficiency and transport accessibility showed obvious regional differences. In 2011, western Hubei showed low-low (Yichang, Enshi and Shiyan) and high-low agglomeration (Xiangyang and Shennongjia). However, in 2017, as Yichang and Enshi changed from low-low to high-low agglomeration, the entire western Hubei changed to a high-low agglomeration. Eastern Hubei showed low-high and high-high agglomeration in both 2011 and 2017, the opposite of the agglomeration characteristics of western Hubei. Except for the changes in the agglomeration of Xiaogan and Xianning during this period, the rest of the region remained unchanged. The spatial agglomeration of overall tourism efficiency and transport accessibility in the central region was not significant (Figure 5a,b). 

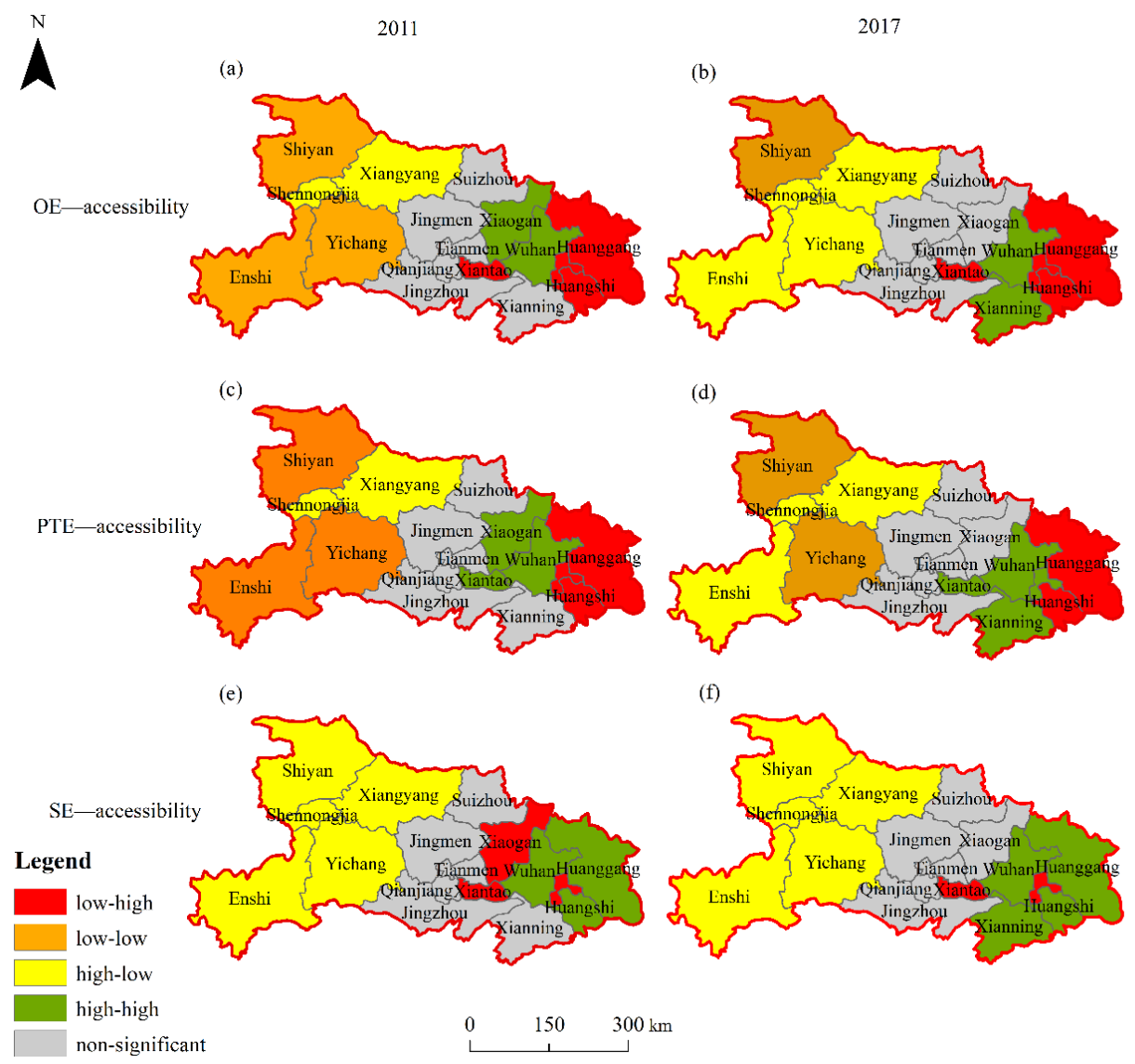

Figure 5. The spatial matching of tourism efficiency and transport accessibility.

The spatial correlation between pure technical efficiency and tourism transport accessibility was similar to that between overall tourism efficiency and transport accessibility. The matching between the two was also poor, and there are few areas with high pure technical efficiency and high accessibility. In addition, there were obvious regional differences in the spatial agglomeration characteristics of them, with low-low agglomeration and high-low agglomeration in the west, low-high agglomeration and high-high agglomeration in the east, and insignificant spatial agglomeration in the central region (Figure $5 c, d$ ). The overall agglomeration characteristics of the province did not change significantly in 2011 and 2017.

Similarly, spatial agglomeration characteristics of the scale efficiency and tourism transport accessibility did not change significantly. Only the eastern high-high agglomeration region had a slight offset. (Xiaogan withdrew from the high-high agglomeration region, while Xianning did the opposite.) In 2011 and 2017, the agglomeration characteristics between the scale efficiency and the transport accessibility in the five regions of western Hubei (Shiyan, Xiangyang, Shennongjia, Yichang, and Enshi) were maintained as high-low agglomerations, while the central region remained insignificant (Figure 5e,f).

Overall efficiency, pure technical efficiency or scale efficiency failed to form an ideal spatial match with transport accessibility. Theoretically, the good traffic conditions of the core cities have a positive spatial spillover effect on the tourism efficiency of the surrounding areas [53], meaning that the improvement of the accessibility of the core cities will promote the development of tourism economy and the improvement of tourism efficiency in the surrounding areas. However, the spatial mismatch between the tourism transport accessibility and tourism efficiency in Hubei Province showed that the transport advantages of core cities have very limited positive spillover effects on tourism efficiency in surrounding areas. In the eastern Hubei region, Wuhan's status as a transport center did not promote the improvement of tourism efficiency in the surrounding areas. It did, however, draw a large amount of capital and labor to the surrounding areas, which restricted 
the improvement of tourism efficiency. In addition, the overall transport accessibility in western Hubei was still low, and there was no transport center that can drive the overall development of tourism in western Hubei through a strong spatial spillover effect. Although Yichang demonstrated its potential to become a transport center in western Hubei in 2017, it is still difficult to drive the development of tourism throughout the entire western Hubei region.

\section{Discussion and Conclusions}

Taking Hubei Province as an example, using DEA model, GIS network analysis, and other methods, we measured the spatiotemporal evolution pattern of the tourism efficiency and transport accessibility, and analyzed the inherent spatiotemporal correlation between them. The main conclusions are as follows.

(1) From 2011 to 2017, the overall tourism efficiency of the province was at relatively high, and the spatial imbalance was gradually weakened. The improvement of pure technical efficiency in western Hubei contributed the most to tourism efficiency, while the effect of scale efficiency was very limited. Therefore, improving the scale efficiency should become the main direction of Hubei Province's follow-up tourism development. In addition, we found that regions with strong resource endowments but low tourism pure technical efficiency can improve tourism pure technical efficiency by strengthening the utility of tourism technology, improving management methods, and optimizing the scale and layout of elements input and then realize the rapid improvement of tourism efficiency. However, for regions with insufficient tourism resource endowments and insufficient scale of tourism industry, even if their resource utilization and technological innovation capabilities are strong, tourism efficiency cannot be improved rapidly in the short term. It can therefore be inferred that the improvement of scale efficiency may be a predicament faced by tourism development in regions with poor tourism resource endowments. In addition, the study showed that macro-regional development strategies and policies such as "Two Circles and One Belt" promote the improvement of tourism efficiency in western Hubei. This showed that the reasonable deployment and implementation of tourism policies and strategies can promote the coordinated and balanced development of regional tourism by improving the regional tourism investment environment, optimizing the input of tourism elements, and improving tourism management methods, and technologies.

(2) From 2011 to 2017, tourism transport accessibility in the province was high and steadily improving, but the spatial distribution pattern of high east and low west remained unchanged. In recent years, the transport network of Hubei Province has improved, especially with the construction of the high-speed rail network, which was the key to improving transport accessibility. However, natural geographic factors such as topography and landforms and a rather backward economy were still the main constraints on the improvement of traffic conditions in western Hubei. The tourism traffic accessibility is very important to the development of regional tourism. Many scholars have studied the role of tourism traffic accessibility in tourism system. Some scholars used the Wuhu Yangtze River Bridge, the Qinghai-Tibet Railway, and Zhangiiajie as examples to explain the role and influence of the traffic system in the development of local tourism $[54,55]$. Li pointed out that tourism traffic will affect the quality of tourism, tourist decision-making, as well as the number of tourists and tourist satisfaction [56]. This paper conducted further research on the role of tourism traffic, and the results showed that traffic accessibility was closely related to the layout and density of the traffic network, and it was greatly affected by natural topography and landforms, and the level of regional economic development was a decisive factor. In addition, the multi-polar transport development pattern is more conducive to the coordinated development of regional tourism. As the transport accessibility in western Hubei has been significantly enhanced, Hubei Province has begun to present a polarized tourism traffic development pattern with Wuhan in the 
east and Yichang in the west, which will help balance the regional development of tourism in Hubei province.

(3) In 2011 and 2017, the overall coupling coordination degree of the tourism efficiency and its decomposition efficiency and transport accessibility in Hubei province were high, and the coupling and coordination degree of eastern Hubei was higher than that in the west. Therefore, each region within the tourism system should formulate and modify its tourism development plans and policies in accordance with the coupling and coordination of tourism efficiency and transport accessibility. During this period, the spatial agglomeration characteristics of the tourism efficiency and its decomposition efficiency and transport accessibility in Hubei Province were manifested as high-low, low-high, low-low, or insignificant agglomeration. There was less highhigh regional agglomeration, indicating that the province's tourism efficiency and its decomposition efficiency were poorly matched with transport accessibility. Therefore, in the future, development of the tourism industry in each region, it is necessary to pay attention match tourism efficiency and transport accessibility at the level of the regional tourism system, the spatial layout of the regional transport network, and the input status of tourism elements.

(4) This paper measured the coordinated development of tourism efficiency and tourism transport in each sub-region in the development process of regional tourism industry through the analysis of coupling coordination. It shows that although the coupling and coordination of tourism efficiency and transport accessibility tend to be optimized, their spatial autocorrelation characteristics may still show up as spatial mismatches. For example, the absolute improvement of the transport accessibility and pure technical efficiency in western Hubei has improved their coupling and coordination. However, compared with the eastern part of Hubei, the level of transport accessibility in western Hubei was still low, so the spatial matching of the transport accessibility and tourism efficiency in western Hubei was still less than ideal. Therefore, in the development of the regional system, it is necessary both to pay attention to the development of tourism and transport in each sub-region, and to optimize the configuration of tourism elements and transport network, so as to reduce regional disparities in the development of tourism in the province.

However, this study may have the following shortcomings. One is that the evaluation of tourism efficiency involves not only economic indicators such as the number of tourists and tourism income, but also psychological indicators, such as tourist experience and comfort. However, since the psychological experience of tourists is difficult to quantify, this paper has not taken it into account. Another limitation is that spatial autocorrelation analysis often requires at least 30 spatial units, but there are only 17 spatial units in this study. This may cause the spatial agglomeration characteristics of tourism efficiency and transport accessibility to show either that low agglomeration is not significant or that high agglomeration is too significant. It may lose statistical significance and compromise the accuracy and reliability of this study. Therefore, further research is needed. Finally, although this paper discusses the potential time-space correlation between regional tourism efficiency and tourism transport accessibility from the perspective of coupling coordination degree and spatial autocorrelation, the deeper quantitative relationship between the two needs to be studied.

Author Contributions: Conceptualization, Y.W. and M.W.; methodology, Y.W.; software, K.L.; validation, Y.W., M.W. and K.L.; formal analysis, M.W.; investigation, M.W.; resources, J.Z.; data curation, J.Z.; writing-original draft preparation, Y.W. and M.W.; writing-review and editing, Y.W.; visualization, K.L.; supervision, Y.W.; project administration, M.W. All authors have read and agreed to the published version of the manuscript.

Funding: This research was funded by "National Natural Science Foundation of China", grant number [41661107]; and was funded by "Natural Science Foundation of Gansu Province", grant number [20JR5RA524]. 
Institutional Review Board Statement: Not applicable.

Informed Consent Statement: Not applicable.

Data Availability Statement: Not applicable.

Conflicts of Interest: The authors declare no conflict of interest.

\section{Appendix A}

Table A1. 2011-2017 Tourism Efficiency Calculation Results in Hubei Province.

\begin{tabular}{|c|c|c|c|c|c|c|c|c|c|c|c|c|}
\hline \multirow{2}{*}{ Area } & \multicolumn{4}{|c|}{ Overall Efficiency } & \multicolumn{4}{|c|}{ Pure Technical Efficiency } & \multicolumn{4}{|c|}{ Scale Efficiency } \\
\hline & 2011 & 2013 & 2015 & 2017 & 2011 & 2013 & 2015 & 2017 & 2011 & 2013 & 2015 & 2017 \\
\hline Wuhan & 1.000 & 1.000 & 1.000 & 1.000 & 1.000 & 1.000 & 1.000 & 1.000 & 1.000 & 1.000 & 1.000 & 1.000 \\
\hline Yichang & 0.429 & 0.533 & 0.646 & 0.716 & 0.463 & 0.569 & 0.704 & 0.745 & 0.928 & 0.937 & 0.918 & 0.961 \\
\hline Xiangyang & 1.000 & 0.964 & 0.878 & 1.000 & 1.000 & 1.000 & 0.951 & 1.000 & 1.000 & 0.964 & 0.923 & 1.000 \\
\hline Jingzhou & 0.946 & 0.987 & 0.977 & 1.000 & 0.996 & 1.000 & 1.000 & 1.000 & 0.950 & 0.987 & 0.977 & 1.000 \\
\hline Jingmen & 0.802 & 0.834 & 0.869 & 0.819 & 0.895 & 0.929 & 0.995 & 0.905 & 0.896 & 0.898 & 0.874 & 0.905 \\
\hline Shiyan & 0.527 & 0.715 & 0.879 & 0.687 & 0.550 & 0.749 & 0.905 & 0.691 & 0.958 & 0.955 & 0.971 & 0.995 \\
\hline Enshi & 0.595 & 0.705 & 0.821 & 1.000 & 0.639 & 0.772 & 0.840 & 1.000 & 0.931 & 0.913 & 0.977 & 1.000 \\
\hline Xianning & 0.841 & 1.000 & 1.000 & 1.000 & 0.873 & 1.000 & 1.000 & 1.000 & 0.963 & 1.000 & 1.000 & 1.000 \\
\hline Xiaogan & 0.689 & 0.629 & 0.659 & 0.548 & 0.868 & 0.762 & 0.739 & 0.636 & 0.794 & 0.825 & 0.892 & 0.861 \\
\hline Suizhou & 0.956 & 0.864 & 0.826 & 0.913 & 1.000 & 1.000 & 1.000 & 1.000 & 0.956 & 0.864 & 0.826 & 0.913 \\
\hline Huangshi & 0.456 & 0.460 & 0.469 & 0.407 & 0.505 & 0.545 & 0.585 & 0.477 & 0.903 & 0.845 & 0.800 & 0.852 \\
\hline Huanggang & 0.576 & 0.567 & 0.561 & 0.516 & 0.581 & 0.674 & 0.688 & 0.560 & 0.992 & 0.840 & 0.815 & 0.921 \\
\hline Ezhou & 0.422 & 0.368 & 0.338 & 0.421 & 0.802 & 0.819 & 0.798 & 0.923 & 0.526 & 0.449 & 0.423 & 0.456 \\
\hline Qianjiang & 0.165 & 0.134 & 0.110 & 0.182 & 1.000 & 1.000 & 1.000 & 1.000 & 0.165 & 0.134 & 0.110 & 0.182 \\
\hline Xiantao & 0.409 & 0.406 & 0.453 & 0.623 & 1.000 & 1.000 & 1.000 & 1.000 & 0.409 & 0.406 & 0.453 & 0.623 \\
\hline Tianmen & 0.400 & 0.366 & 0.308 & 0.245 & 1.000 & 1.000 & 1.000 & 1.000 & 0.400 & 0.366 & 0.308 & 0.245 \\
\hline Shennongjia & 1.000 & 1.000 & 1.000 & 1.000 & 1.000 & 1.000 & 1.000 & 1.000 & 1.000 & 1.000 & 1.000 & 1.000 \\
\hline Average value & 0.660 & 0.678 & 0.694 & 0.710 & 0.834 & 0.872 & 0.894 & 0.879 & 0.810 & 0.787 & 0.781 & 0.819 \\
\hline
\end{tabular}

\section{References}

1. Wu, Y.F.; Hannam, K.; Xu, H.G. Reconceptualising home in seasonal Chinese tourism mobilities. Ann. Tour. Res. 2018, 73, 71-80. [CrossRef]

2. Cao, F.; Huang, Z.; Wu, J. The relationship between tourism efficiency measure and location accessibility of Chinese national scenic area. Acta Geogr. Sin. 2012, 62, 1686-1697.

3. Jiang, H. China's high-speed rail network space efficiency and study on the relationship between the supply and demand in perspective of accessibility. Resour. Environ. Yangtze Basin. 2019, 28, 2299-2308.

4. Yin, P.; Li, Z.B.; Prideaux, B. The impact of high-speed railway on tourism spatial structures between two adjoining metropolitan cities in China: Beijing and Tianjin. J. Transp. Geogr. 2019, 80, 102495. [CrossRef] [PubMed]

5. Song, M.L.; Li, H. Estimating the efficiency of a sustainable Chinese tourism industry using bootstrap technology rectification. Technol. Forecast. Soc. Chang. 2019, 143, 45-54. [CrossRef]

6. Corne, A. Benchmarking and tourism efficiency in France. Tour. Manag. 2015, 51, 91-95. [CrossRef]

7. Cao, F.D.; Huang, Z.F.; Jin, C.; Xu, M. Chinese national scenic areas' tourism efficiency: Multi-scale fluctuation, prediction and optimization. Asia Pac. Tour. Res. 2015, 21, 570-595. [CrossRef]

8. Baker, M.; Riley, M. New perspectives on productivity in hotels: Some advances and new directions. Int. Hosp. Manag. 1994, 13, 97-311. [CrossRef]

9. Michael, D.H.; Keith, C. Employee performance cues in a hotel service environment: Influence on perceived service quality, value and word-of-mouth intentions. J. Bus. Res. 1996, 35, 207-215.

10. Barros, C.P.; Matias, A. Assessing the efficiency of travel agencies with a stochastic cost frontier: A Portuguese case study. Int. Tour. Res. 2006, 8, 367-379. [CrossRef]

11. Hu, Y.; Mei, L.; Wei, J.G. Spatial differentiation and dynamic mechanism of regional travel agency efficiency in China based on GWR model. Sci. Geogr. Sin. 2018, 38, 107-113.

12. Ren, Y.; Liu, W.; Zhao, K.; Zhao, J. The measurement and evaluation of the operating efficiency of China's listed Tourism Companies: An empirical analysis based on the mixed DEA model. Tour. Trib. 2017, 32, 27-36.

13. Cao, F.; Huang, Z.; Xu, M.; Wang, K. Spatial-temporal pattern and influencing factors of tourism efficiency and the decomposition efficiency in Chinese scenic areas: Based on the Bootstrap-DEA method. Geogr. Res. 2015, 34, 2395-2408. 
14. Cao, F.; Huang, Z.; Fenglong, Y.U.; Wu, L. The spatial evolution of travel efficiency of China's National Scenic Areas and its driving mechanism. Geogr. Res. 2014, 33, 1151-1166.

15. Geurs, K.; Wee, B. Accessibility evaluation of land-use and transport strategies review and research directions. J. Transp. Geogr. 2004, 12, 127-140. [CrossRef]

16. Ma, X.; Bao, J. Regional difference and spatial patterns of the tourism efficiency in Chinese primary tourist cities. Hum. Geogr. 2010, 25, 105-110.

17. Junyang, H.E.; Ling, H.; Qizhong, D. Inbound tourism development efficiency and influencing factors in inland nine Provinces of the Pan-Pearl River delta. Econ. Geogr. 2016, 36, 195-201.

18. Wei, J.; Hu, J.; Zhu, L.; Yu, J. Spatial-temporal differentiation and influencing mechanism of tourism development efficiency in Hubei Province and Anhui Province. Econ. Geogr. 2018, 38, 187-195.

19. Zhu, C.; Yue, H.; Yan, H.; Li, T. Study on the efficiency of regional tourism industry in China based on Stochastic Frontline Production and Cost Function Estimation. Tour. Trib. 2009, 24, 18-22.

20. Li, L. The Optimization of Travel Agency Value Chain Based on Production Function; Xiamen University: Xiamen, China, 2009.

21. Duan, Z.Y.; Wang, X.; Liu, D.L.; He, J. Research status and prospects of tourism transportation at home and abroad. Tour. Guide. 2018, 2, 70-89.

22. Li, Y.; Tan, H. Tourism transportation planning practice of Zhexi reservoir in Anhua County Based on the concept of green transportation. Hunan Transp. Sci. Technol. 2020, 46, 134-137.

23. Pengian, D.M. Practice of tourism transportation planning in Shenzhen Dameisha scenic area led by public transportation. Urban Public Transp. 2019, 4, 54-56.

24. Wang, F.; Liu, A.L.; Ming, Q.Z.; Zhang, B.F. Analysis of spatial coupling coordination between transport superiority and tourism industry in Yunnan. World Reg. Stud. 2014, 23, 166-175.

25. Yu, F.F.; Hu, W.H.; Rong, H.F. Coordinated development about tourism economy and transportation in medium and small cities: Chizhou as example. Sci. Geogr. Sin. 2015, 35, 1116-1122.

26. Guo, K.; Wang, S.B.; Li, B.; Peng, F.; Wang, D. The spatial effect of Harbin-Dalian high-speed rail to the northeast city tourism economic link. Sci. Geogr. Sin. 2016, 36, 521-529.

27. Yang, Z.Y.; Lu, S. The impacts of traffic improvements on spatial structure of regional tourism: A case of Southern Anhui. Sci. Geogr. Sin. 2013, 33, 806-814.

28. Zhou, F.R.; Wu, F.; Wu, P.; Li, J.L.; Wu, C. Comparative research on the transportation accessibility of main inbound tourism cities in China. Tour. Trib. 2016, 31, 12-22.

29. Iang, H.B.; Liu, G.; Iang, L. An analysis of the accessibility of China's tourist attractions under the impact of High-speed Railway. Tour. Trib. 2014, 29, 58-67.

30. Jin, C.; Lu, Y.Q.; Zhang, L.; Xu, J. An analysis of accessibility of scenic spots based on land traffic network: A case study of Nanjing. Geogr. Res. 2009, 28, 246-258.

31. Paninghu, C.Y. Spatial Accessibility of scenic spot at 4 A level and above in China. Sci. Geogr. Sin. 2012, 32, 1321-1327.

32. Li, X.; Liu, C. Accessibility and service of Shenyang's urban parks by network analysis. Acta Ecol. Sin. 2009, 29, $1554-1562$.

33. Gang, C.; Xiang, H.; Dajun, L.; Chen, Z. Special analysis of transportation accessibility and its correlations with tourism economic linkage of Hubei Province. Tour. Forum. 2012, 5, 62-66.

34. Weng, J.; Yang, K.Z. Spatial structure of tourism system: Spatial model for monopolistic competition with asymmetry. Syst. Eng. Theory Pract. 2007, 27, 76-82. [CrossRef]

35. Fu, Q.; Liu, D.; Hu, J.; Xie, S.; Gong, J.; Chen, X. Network structure and optimization research on the Hubei Province tourist Flow. Econ. Geogr. 2015, 35, 191-196.

36. Han, L.; Xie, S.; Wang, H. Spatial distribution and influencing factors of geographical indication products in Hubei Province. Agric. Mod. Res. 2018, 39, 865-874.

37. Shi, Y.Y. Research on the Relationship between Etymological Types and Geographical Environment Elements of Administrative Place Names in Hubei Province; Shanxi Normal University: Shanxi, China, 2016.

38. Sun, H.; Xu, N.; Song, Z. Research on Tourism efficiency evaluation of red tourism cities in China based on data envelopment model. China Tour. Rev. 2021, 4, 13-25.

39. Pang, X. Analysis on the operational efficiency of listed tourism companies-Based on data envelopment analysis. Tour. Overv. 2021, 4, 76-79.

40. Zhou, J.J. Calculation of the operating efficiency of star hotels in the Yangtze River Economic Belt Based on basic DEA. Finance Acc. Commun. 2020, 4, 106-110.

41. Xu, Q.; Cheng, H. Spatiotemporal characteristics and influencing factors of coupling coordination between tourism ecological efficiency and tourism green innovation efficiency in China. J. Zhongzhou Univ. 2021, 38, 33-40.

42. Li, H.; Sun, R. Design and optimization of cruise tourism eco efficiency evaluation based on DEA-SBM model. China Water Transp. 2021, 4, 49-51.

43. Li, X. Analysis on the efficiency of poverty alleviation by tourism in contiguous destitute areas of Guizhou Province Based on DEA. J. Guizhou Radio Telev. Univ. 2021, 29, 63-68.

44. Podinovski, V.V. DEA models for the explicit maximisation of relative efficiency. Eur. J. Oper. Res. 2011, 131, 572-586. [CrossRef] 
45. Banker, R.D.; Charnes, A.; Cooper, W.W. Some models for estimating technical and scale inefficiencies in data envelopment analysis. Manag. Sci. 1984, 30, 1078-1092. [CrossRef]

46. Chen, Y.Z.; Shen, S.F.; Chen, T.; Yang, R. Path optimization study for vehicles evacuation based on Dijkstra Algorithm. Proc. Eng. 2014, 71, 159-165. [CrossRef]

47. Chen, Y.; Wei, F. Spatial relations and coordinated development of characteristic villages and A-level scenic spots in Guangxi. Tour. Tribune 2020, 35, 113-126.

48. Ji, X.; Zhang, L.; Chen, F.; Cui, M. Coupling and spatial differences between the development level of self-drive tourism and tourism transportation accessibility in Yunnan. Econ. Geogr. 2016, 36, 195-201.

49. Anselin, L. Local indicators of spatial association-LISA. Geogr. Anal. 1995, 27, 93-115. [CrossRef]

50. Xu, D.; Huang, Z.; Hu, X.; Lv, L.; Cao, F. The spatial pattern evolution and its influencing factors of county-Scale tourism efficiency in the Zhejiang Province. Econ. Geogr. 2018, 38, 197-207.

51. Tobler, W. A computer movie simulating urban growth in the Detroit region. Econ. Geogr. 1970, 46, 234-240. [CrossRef]

52. Huang, S.; Li, Y.; Li, R. Spatial relationship and formation mechanism of geological relics and ethnic cultural resources in western Guangxi, China. Acta Geogr. Sin. 2015, 70, 1434-1448.

53. Zhao, L.; Fang, C.; Wu, X. Tourism development, spatial spillover and economic growth: An empirical evidence from China. Tour. Tribune. 2014, 29, 16-30.

54. Wang, Z. An Empirical Analysis of the Impact of Tourism Transportation on the Development of Tourism Industry-Taking Zhangjiajie as an example. Theory Pract. Finance Econ. 2009, 30, 112-116.

55. Zhang, J.; Lu, L. Wuhu Yangtze River Bridge and the improvement of tourism traffic conditions in Anhui. Hum. Geogr. 2002, $4,75-79$.

56. Xiaoming, L. The role of tourism transportation in tourism-taking the railway system as an example. Commer. Stories. 2015, 4, 24-26. 